\title{
Infections are a global issue: Infection addresses global issues
}

\author{
M. P. Grobusch • G. Calleri · J. R. Bogner
}

Published online: 26 September 2012

(C) Springer-Verlag 2012

\begin{abstract}
Infections are of unifying global concern, despite regional differences in disease epidemiology, clinical appearance and the instruments to tackle them. The primary aim of Infection is "to be a forum for the presentation and discussion of clinically relevant information on infectious diseases... from all over the world". To that end, and as a reflection of the global burden of infectious diseases, we intend to increase the number of high-quality contributions from authors addressing the aetiology, pathogenesis, diagnosis and treatment of infectious diseases from outside Europe and the affluent North (Chang et al. Infection 40:359-365, 2012; Misra et al. Infection 40:125-130, 2012). The Editorial Board of Infection envisages the journal as an interface between where infectious diseases meet and mix between "North and South"-i.e., the field of travel medicine-frequently functioning as a sentinel for altered/novel disease activities that are encountered as imported conditions. With the change in generation on the Editorial Board, Infection aims to expand the areas of tropical medicine, travel medicine
\end{abstract}

\footnotetext{
M. P. Grobusch ( $\square)$

Center of Tropical Medicine and Travel Medicine, Division of Internal Medicine,

Department of Infectious Diseases,

Academic Medical Center, University of Amsterdam,

Amsterdam, The Netherlands

e-mail: m.p.grobusch@amc.uva.nl

G. Calleri

Travel Medicine Unit, Division of Infectious Diseases,

Amedeo di Savoia Hospital, Turin, Italy

\section{J. R. Bogner}

Department of Infectious Diseases, Med Klinik und Poliklinik

IV, University Hospital of Munich, Downtown Campus,

Munich, Germany
}

and global health with its own section editors (GC and MPG). Contributions from outside Europe are actively encouraged.

Keywords Infection - Travel medicine - Emerging infectious diseases - Tropical medicine - Tropical infectious diseases

In light of the rapidly growing body of knowledge on the global control of infectious diseases, as well as the recent enormous investments that have been made in this field, there is an ever-increasing need to provide the appropriate platform to research results. The changing epidemiology of infectious diseases on a large scale may also change the order of magnitude on which those diseases are encountered in Europe. For example, with the epidemology of Chagas' disease, one of the infectious diseases propagated by the current global urbanization trend, changing rapidly to an urban pattern, this condition is expected to be encountered more frequently as an imported disease [3-5]. Travellers now reach every corner of the globe, frequently returning home with unwanted-even life-threateningsouvenirs [6,7] and occasionally sporting unexpected diseases not necessarily always fitting into the scheme of what epidemiologists know or expect [8-10].

There is a strong move towards a better control of neglected tropical diseases [11]; it is no longer a taboo to think about malaria elimination, if not eradication, because it has become an achievable goal. With its broad scope, Infection has the capacity to serve as a platform for discussion of those important topics. Moreover, international collaboration among centres of excellence has been recognized as vital in both the clinical and the laboratory settings. Large clinical, epidemiologic and laboratory 
networks throughout the world are increasing their work in surveillance and research (Eurotravnet/GeoSentinel, Tropnet, Envid, Goarn, among others). Infection relies on those networks to cover the variety of infectious diseases which are moving throughout the world and to prompt professionals to face the increasing burden of new and unexpected experiences.

Against this backdrop, the scientific attention of Infection's "international section" will be focusing on preventive medicine on the one hand, through reporting on progress on vaccinations, chemoprophylaxis and disease prevention strategies, and practice-related laboratory and clinical medicine on the other, including case reporting, which should not be underestimated as a clinical learning tool [12].

It will be important to keep the readers of Infection informed of not only important new developments in this section, but also to show examples of imported diseases using concise and outstanding case reports and manuscripts in the "Images" section that represent clinical pictures with an effect of "first sight diagnosis".

Although a broad range of journals specifically address travel medicine, tropical infectious diseases and related public health issues, it is still not only desirable but necessary to see more journals, in this case Infection, expand into this area, reflecting the fact that infectious agents and infectious diseases respect neither geographical borders nor medical specialty boundaries.

\section{References}

1. Chang HC, Lin MC, Liu SF, Su MC, Fang WF, Chen YC, et al. The clinical differences between dengue and scrub typhus with acute respiratory failure in southern Taiwan. Infection. 2012; 40:359-65.

2. Misra UK, Kalita J, Maurya PK, Kumar P, Shankar SK, Mahadevan A. Dengue-associated transient muscle dysfunction: clinical, electromyography and histopathological changes. Infection. 2012; 40:125-30.

3. Alirol E, Getaz L, Stoll B, Chappuis F, Loutan L. Urbanisation and infectious diseases in a globalised world. Lancet Infect Dis. 2010;10:131-41.

4. Gautret P, Cramer J, Field V, Caumes E, Jensenius M, GkraniaKlotsas E, et al. Infectious diseases among travellers and migrants in Europe. EuroTravNet 2010. Euro Surveill. 2012; 17(26):1-11.

5. Tappe D, Demmer P, Echterhoff U, Weskamp R. Two cases of presumably travel-related subcutaneous cysticercosis. Infection. 2010;38:152-3.

6. Herbinger KH, Fleischmann E, Weber C, Perona P, Löscher T, Bretzel G. Epidemiological, clinical, and diagnostic data on intestinal infections with Entamoeba histolytica and Entamoeba dispar among returning travelers. Infection. 2011;39:527-35.

7. Schmidt-Chanasit J, Tenner-Racz K, Poppert D, Emmerich P, Frank C, Dinges C, et al. Fatal dengue hemorrhagic fever imported into Germany. Infection. 2012;40:441-3.

8. Inojosa WO, Scotton PG, Fuser R, Giobbia M, Paolin A, Maresca $\mathrm{MC}$, et al. West Nile virus transmission through organ transplantation in north-eastern Italy: a case report and implications of pre-procurement screening. Infection. 2012. doi:10.1007/s15010012-0263-4.

9. Centers for Disease Control and Prevention (CDC). Notes from the field: acute muscular sarcocystosis among returning travellers-Tioman Island, Malaysia, 2011. MMWR Morb Mortal Wkly Rep. 2012;61:37-8.

10. Casabianca A, Marchetti M, Zallio F, Feyles E, Concialdi E, Ferroglio E, Biglino A. Seronegative visceral leishmaniasis with relapsing and fatal course following rituximab treatment. Infection. 2011;39:375-8.

11. Garg RK, Malhotra HS, Gupta A, Kumar N, Jain A. Concurrent dengue vírus and Japanese encephalitis vírus infection of the brain: is it co-infection or co-detection? Infection. 2012. doi: 10.1007/s15010-012-0284-2.

12. Zhang Y, MacArthur C, Mublia L, Baker S. Control of neglected tropical diseases needs a long-term commitment. BMC Med. 2010;8:67. 